\title{
Hydraulic Fluid Type and Remediation Practices on Hydraulic Leak Injury to Creeping Bentgrass Putting Greens
}

\author{
John E. Kaminski ${ }^{1}$, Tim T. Lulis ${ }^{1}$, and Travis R. Russell ${ }^{1}$
}

\section{AdDitionAL INDEX WORDs. phytotoxicity, turfgrass}

SUMMARY. Equipment with hydraulic implements are often used to maintain turfgrass surfaces. Hydraulic implements can malfunction and lead to leaks or spills of hydraulic fluid, which is phytotoxic to turfgrass. Previous research has documented extensively hydraulic fluid injury on warm-season turfgrasses, but these effects have not been evaluated on cool-season grasses and warrant further investigation.

Therefore, the objectives of this study were to compare phytotoxicity of petroleum, vegetable, and synthetic hydraulic fluids on a creeping bentgrass (Agrostis stolonifera) putting green and to evaluate the influence of postapplication remediation practices on reducing turfgrass injury. Turfgrass injury was evaluated over a 4-week period in 2011 and 2012 after simulated hydraulic fluid leak and remediation practices were applied. Complete necrosis was observed after 28 days for all hydraulic fluid types. However, water rinse (RO) or detergent soap solution drench followed by brushing in/water rinse (SBR) remediation practices effectively eliminated turfgrass injury by the end of the 4-week period for synthetic polyalkylene glycol fluid treatments, but no other hydraulic fluid types. Turfgrass managers might consider the synthetic polyalkylene glycol hydraulic fluid tested in this study as a less phytotoxic alternative to petroleum hydraulic fluids if a remediation practice is implemented after a leak or spill.

$\mathrm{T}$ urfgrass managers routinely use mowers and other machinery that operate hydraulic implements to maintain turfgrass surfaces and surrounding landscapes. These hydraulic implements rely on highly pressurized fluids to move various components and activate motors on equipment. Not unlike other pieces of equipment, hydraulic implements have the capability to malfunction or break down during operation. When this happens, highly pressurized and hot hydraulic fluid has the potential to leak or spill onto the turfgrass. Most conventional hydraulic fluids are phytotoxic to turfgrass and, if the leak is not detected and turf not immediately remediated, can create extensive turfgrass necrosis (Johns and Beard, 1979).

Conventionally, hydraulic fluids are petroleum-based oils comprised

Received for publication 8 June 2019. Accepted for publication 18 Sept. 2019.

Published online 29 October 2019

${ }^{1}$ Department of Plant Science, The Pennsylvania State University, 21 Tyson Building, University Park, PA 16802

J.E.K. is the corresponding author. E-mail: kaminski@ psu.edu.

This is an open access article distributed under the CC BY-NC-ND license (https://creativecommons.org/ licenses/by-nc-nd/4.0/).

https://doi.org/10.21273/HORTTECH04447-19 significantly of hydrocarbons. Hydrocarbons are toxic to plants and animal life, and leaks or spills can create long-term environmental hazards (Aislabie et al., 2004; Bai and $\mathrm{Li}, 2013$ ). In addition, these introduced hydrocarbons are hydrophobic and coat soil particles while also increasing carbon-to-nitrogen ratios in the soil that limit plant nutrient availability (Aislabie et al., 2004; Everett, 1979).

Conventional petroleum-based hydraulic fluids leaks often result in rapid phytotoxic effects on turfgrass. Reports have noted drying and curling of leaves that darken in color immediately after a spill, with leaf chlorosis taking place within $24 \mathrm{~h}$ on 'Tifgreen' hybrid bermudagrass (Cynodon dactylon $\times$ C. transvaalensis) (Elliott and Prevatte, 1995; Johns and Beard, 1979). Complete necrosis to all aboveground plant tissue has been observed within $48 \mathrm{~h}$, and residual effects in the soil are reported to impact turfgrass performance from 4 months to 1 year after the spill (Bai and Li, 2013; Elliott and Prevatte, 1995). In addition, Berndt et al. (2018a) documented significant reductions in visual green color for the first $3 \mathrm{~d}$ after a petroleum-based hydraulic fluid spill on a 'TifEagle' hybrid bermudagrass putting green using digital image analysis. After $3 \mathrm{~d}$, the turf appeared fully necrotic and there were no further significant reductions in visual green color.

During the early 1990s, vegetablebased oils for hydraulic fluids were developed as an environmentally safe and nontoxic alternative to petroleum-based fluids (Cheng et al., 1991). When tested on turfgrass, both petroleum- and vegetable-based fluids resulted in complete leaf necrosis. However, the rate of necrosis was much slower on turfgrass applied with the vegetable hydraulic fluid, occurring $7 \mathrm{~d}$ after application compared with petroleum hydraulic fluid producing full necrosis after $2 \mathrm{~d}$ (Elliott and Prevatte, 1995). No differences in percent turf recovery were observed, but chlorosis as a result of petroleum-based fluid remaining in the soil for a longer period was still evident more than 1 year later. Berndt et al. $(2018 \mathrm{~b})$ provided further confirmation when simulated spills resulted in significantly greater injury area for petroleum-based fluid compared with a vegetable oil-based fluid over a 139 $\mathrm{d}$ period. Nonlinear regression modeling and simulation of these data predicted full recovery after 494 and $303 \mathrm{~d}$ for petroleum and vegetable oil hydraulic fluids, respectively.

In addition, synthetic hydraulic fluids are often designed to improve lubrication, stability, and optimal performing conditions in comparison with petroleum- and vegetable/ seed-based oils and are derived from six major base stock types including

\begin{tabular}{llll}
\hline $\begin{array}{l}\text { Units } \\
\text { To convert U.S. to SI, } \\
\text { multiply by }\end{array}$ & U.S. unit & SI unit & $\begin{array}{l}\text { To convert SI to U.S., } \\
\text { multiply by }\end{array}$ \\
\hline 29.5735 & $\mathrm{fl} \mathrm{oz}$ & $\mathrm{mL}$ & 0.0338 \\
0.3048 & $\mathrm{ft}$ & $\mathrm{m}$ & 3.2808 \\
3.7854 & gal & $\mathrm{L}$ & 0.2642 \\
25.4 & inch $(\mathrm{es})$ & $\mathrm{mm}$ & 0.0394 \\
6.8948 & $\mathrm{psi}$ & $\mathrm{kPa}$ & 0.1450 \\
$\left({ }^{\circ} \mathrm{F}-32\right) \div 1.8$ & ${ }^{\circ} \mathrm{F}$ & ${ }^{\circ} \mathrm{C}$ & $\left({ }^{\circ} \mathrm{C} \times 1.8\right)+32$ \\
& & & \\
\hline
\end{tabular}


polyalkylene glycols and diesters (Beatty and Greaves, 2006; Sumerlin, 2010). Synthetic hydraulic fluids were first developed for the turfgrass industry beginning in 2005 and were marketed as biodegradable and less phytotoxic than petroleum and vegetable oil hydraulic fluids (Berndt, 2007). In a greenhouse experiment on 'TifEagle' ultradwarf hybrid bermudagrass, a synthetic polyalkylene hydraulic fluid resulted in $40 \%$ necrosis $4 \mathrm{~d}$ after treatment (DAT) but recovered completely by 10 DAT, whereas turfgrass treated with vegetable and petroleum hydraulic fluid were completely dead (Berndt, 2007). In field experiments on putting greens of multiple warm-season turfgrass varieties, Berndt (2007) reported that a synthetic hydraulic fluid treatment consistently produced significantly smaller injury area, less necrosis, and quicker recovery than both vegetable and petroleum oil treatments. Furthermore, injured area on a 'TifEagle' hybrid bermudagrass putting green decreased by $30.9 \%$ from 1 DAT to 38 DAT following a simulated spill of a synthetic hydraulic fluid, whereas petroleum- and vegetable oil-based fluids increased the injury area by $120.3 \%$ and $73.9 \%$, respectively (Berndt et al., 2017). Despite these observations, synthetic hydraulic fluids have yet to be tested on cool-season turfgrass putting greens. Considering the less aggressive rhizomatous growth habit of cool-season turfgrasses such as creeping bentgrass (Agrostis stolonifera), the potential for synthetic hydraulic fluid to serve as a viable replacement to conventional petroleum-based hydraulic fluids requires additional evaluation.

In addition, posthydraulic spill remediation practices are important in limiting turfgrass phytotoxicity and necrosis, and accelerating recovery. Powell (1981) evaluated various methods of remediation practices after spills on a 'Penncross' creeping bentgrass putting green that included various detergents soaps, activated charcoal, and calcined clay. A diluted detergent applied to the turfgrass immediately after spill, scrubbed in, and rinsed thoroughly was the recommended practice to promote the quickest recovery (Powell, 1981). In a separate study on 'Tifgreen' hybrid bermudagrass, a granular detergent drenched to form suds and then rinsed off provided $90 \%$ recovery within 4 weeks, whereas activated

Table 1. Analysis of variance table of turfgrass injury evaluation main effects and interactions on a 'Penn A-4' creeping bentgrass putting green in 2011 and 2012. Probability values in bold are highest order significant $(P \leq 0.05)$ treatments interactions that warrant further discussion.

\begin{tabular}{|c|c|c|c|c|}
\hline \multirow[b]{3}{*}{ Effect } & \multicolumn{4}{|c|}{ Turfgrass injury } \\
\hline & \multicolumn{2}{|c|}{2011} & \multicolumn{2}{|c|}{2012} \\
\hline & df & $P>F$ & $\overline{\mathrm{df}}$ & $P>\mathrm{F}$ \\
\hline Block & 3 & - & 3 & - \\
\hline Hydraulic fluid & 4 & $<0.0001$ & 4 & $<0.0001$ \\
\hline Remediation & 2 & $<0.0001$ & 2 & $<0.0001$ \\
\hline Hydraulic fluid $\times$ Remediation & 8 & $<0.0001$ & 8 & $<0.0001$ \\
\hline Days after treatment (DAT) & 4 & $<0.0001$ & 4 & $<0.0001$ \\
\hline Hydraulic fluid $\times$ DAT & 16 & $<0.0001$ & 16 & $<0.0001$ \\
\hline Remediation $\times$ DAT & 8 & $<0.0001$ & 8 & $<0.0025$ \\
\hline Hydraulic fluid $\times$ Remediation $\times$ DAT & 32 & $<0.0001$ & 32 & $<0.0001$ \\
\hline
\end{tabular}

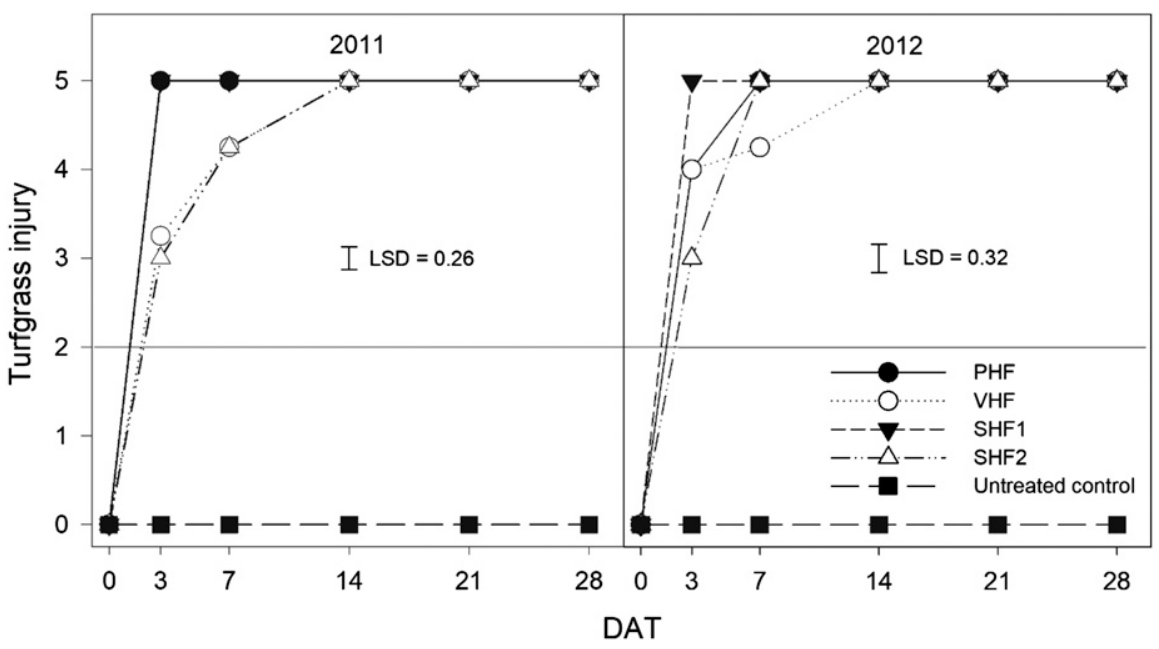

Fig. 1. Visual turfgrass injury severity ratings (0-5 scale, where 2 is minimum acceptability and $\mathbf{5}$ is brown, dead turf) of a creeping bentgrass putting green as affected by hydraulic fluid treatment with no remediation practice by days after treatment (DAT) in 2011 and 2012. The line at the turfgrass severity rating of 2 indicates a visual reference of minimum acceptability. The least significant difference (LSD) bar indicates the LSD value to make treatment comparisons within the evaluation date. PHF, petroleum hydraulic fluid; VHF, vegetable hydraulic fluid; SHF1, synthetic polyalkylene hydraulic fluid; SHF2, synthetic diester hydraulic fluid.

charcoal and calcined clays achieved $25 \%$ and $15 \%$ recovery, respectively (Johns and Beard, 1979). However, visual observations have indicated that high concentrations and quantities of detergent soap could cause phytotoxicity to the turf, exacerbating phytotoxicity even further (Berndt, 2018). Berndt et al. (2017) used nonlinear regression modeling of the hydraulic fluid injury area to demonstrate that a water rinse after spill reduced healing time from 224 to $65 \mathrm{~d}$ from spill of a synthetic polyalkylene glycol fluid on a 'TifEagle' hybrid bermudagrass green. However, the water rinse treatment was not effective for petroleum and vegetable hydraulic fluid spills, with a healing time longer than 400 $\mathrm{d}$ regardless of whether rinse treatment was applied. If synthetic hydraulic fluids are to become widely adapted for use in the turfgrass industry, additional evaluation of remediation methods after synthetic hydraulic fluid spills on cool-season turfgrass is needed to develop best management practices to limit turfgrass injury and promote recovery.

Therefore the objectives of this study were 1) to compare the phytotoxic effects of four hydraulic fluids of different types when applied to a creeping bentgrass putting green 


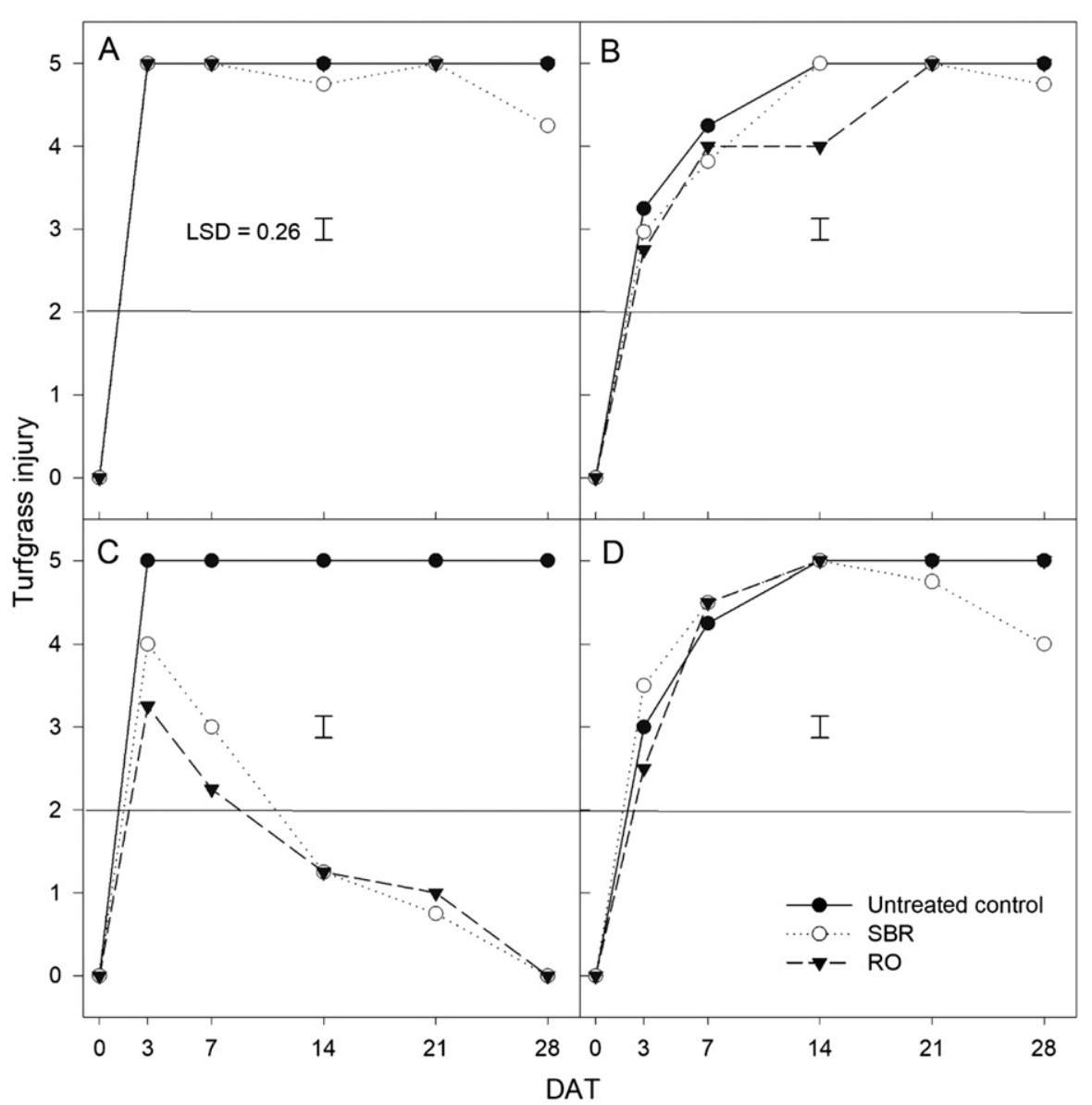

Fig. 2. Visual turfgrass injury severity ratings ( $0-5$ scale, where 2 is minimum acceptability and 5 is brown, dead turf) of a creeping bentgrass putting green as affected by water rinse only (RO), detergent soap solution + brushed in + water rinse (SBR), and no remediation practice (untreated control) after simulated spill of (A) petroleum hydraulic fluid, (B) vegetable hydraulic fluid, (C), synthetic polyalkylene hydraulic fluid, and (D) synthetic diester hydraulic fluid by days after treatment (DAT) in 2011. The line at the turfgrass severity rating of 2 indicates a visual reference of minimum acceptability. The least significant difference (LSD) bar indicates the LSD value to make treatment comparisons within the evaluation date.

and 2) to determine the influence of postapplication remediation treatments on reducing injury.

\section{Materials and methods}

EXPERIMENTAL AREA. This trial was conducted during the 2010 and 2011 growing seasons on a mature 'Penn A-4' creeping bentgrass modified, sand-based, root-zone putting green at the Joseph E. Valentine Turfgrass Research Center in University Park, PA. The trial was initiated on 29 Aug. and concluded 26 Sept. 2011 , and was repeated from 27 Aug. to 24 Sept. 2012. Soil physical properties of the putting green were a sandy loam with a $\mathrm{pH}$ of 7.1 and $1.8 \%$ organic matter. Mowing was performed six times weekly at $3.1 \mathrm{~mm}$.

Treatments. Five hydraulic fluid treatments were applied to the turfgrass surface as follows: one conventional petroleum-based hydraulic fluid [PHF (Toro Premium All Season; Toro, Bloomington, MN)], one vegetable oil hydraulic fluid [VHF (Greens Care Plus 46; Terresolve Technologies, Eastlake, $\mathrm{OH}$ )], two synthetic hydraulic fluidsa polyalkylene glycol [SHFl (EnBio TCS; EnBio Industries, Lake Worth, FL)] and a diester [SHF2 (Mobil EAL Envirosyn 46H; Mobil, Irving, TX)] - and an untreated control. Each hydraulic fluid was heated to a temperature of $60{ }^{\circ} \mathrm{C}$ with an electric ceramic hot plate to mimic temperature during equipment operation. Fluid treatments were applied linearly at a flow rate of $15 \mathrm{~mL} /$ $\mathrm{ft}$ to ensure consistent spill width using a funnel-equipped oil can (Plews Funnel 75-444; Plews-Edellman, Dixon, IL) within individual $3 \times 6$-ft plots.

Each hydraulic fluid treatment was subjected to three postapplication remediation treatments. The three remediation treatments included RO, SBR, and no remediation (untreated control) applied within 12 min after application. RO treatments were applied to the fluid spill with a carbon dioxide backpack sprayer at 50 psi equipped with a single flat-fan nozzle (TP8015E; TeeJet, Wheaton, IL) and delivered a total of $8.5 \mathrm{~L}$ water to each spill area. For SBR treatments, $333 \mathrm{~mL}$ of $5 \%$ soapy detergent water (Ajax Dish Liquid; Colgate-Palmolive Co., New York, NY) was applied along the fluid spill as described previously and then was scrubbed in with a stiff-bristled brush perpendicular to the fluid spill. This process was repeated until $2 \mathrm{~L}$ of the detergent soap-water solution had been applied to the turfgrass, at which point a 6.5 - $\mathrm{L}$ water rinse was applied.

Evaluations. Ambient temperature, relative humidity, and wind speed were recorded at the time of application using a handheld weather meter (Kestrel 3000; Nielsen-Kellerman, Boothwyn, PA). Turfgrass injury was evaluated on 0 to 5 scale, where $0=$ no visible turfgrass injury, $2=$ minimal acceptable injury, and $5=$ brown or dead turfgrass. Evaluations of turfgrass injury were evaluated $3,7,14,21$, and 28 DAT.

Statistical Design AND ANALYsIs. This trial was designed as a $5 \times 3$ factorial design in a randomized complete block design with four replications. Each replication included treatments of simulated hydraulic fluid spills from five different hydraulic fluid treatment factors that included PHF, VHF, SHFl, SHF2, and an untreated control. In addition, each replication included three remediation factors of $\mathrm{RO}$, SBR, and an untreated control posthydraulic spill in combination with each hydraulic fluid treatment.

Data were analyzed as a repeatedmeasures experiment using the PROC MIXED procedure of SAS (version 


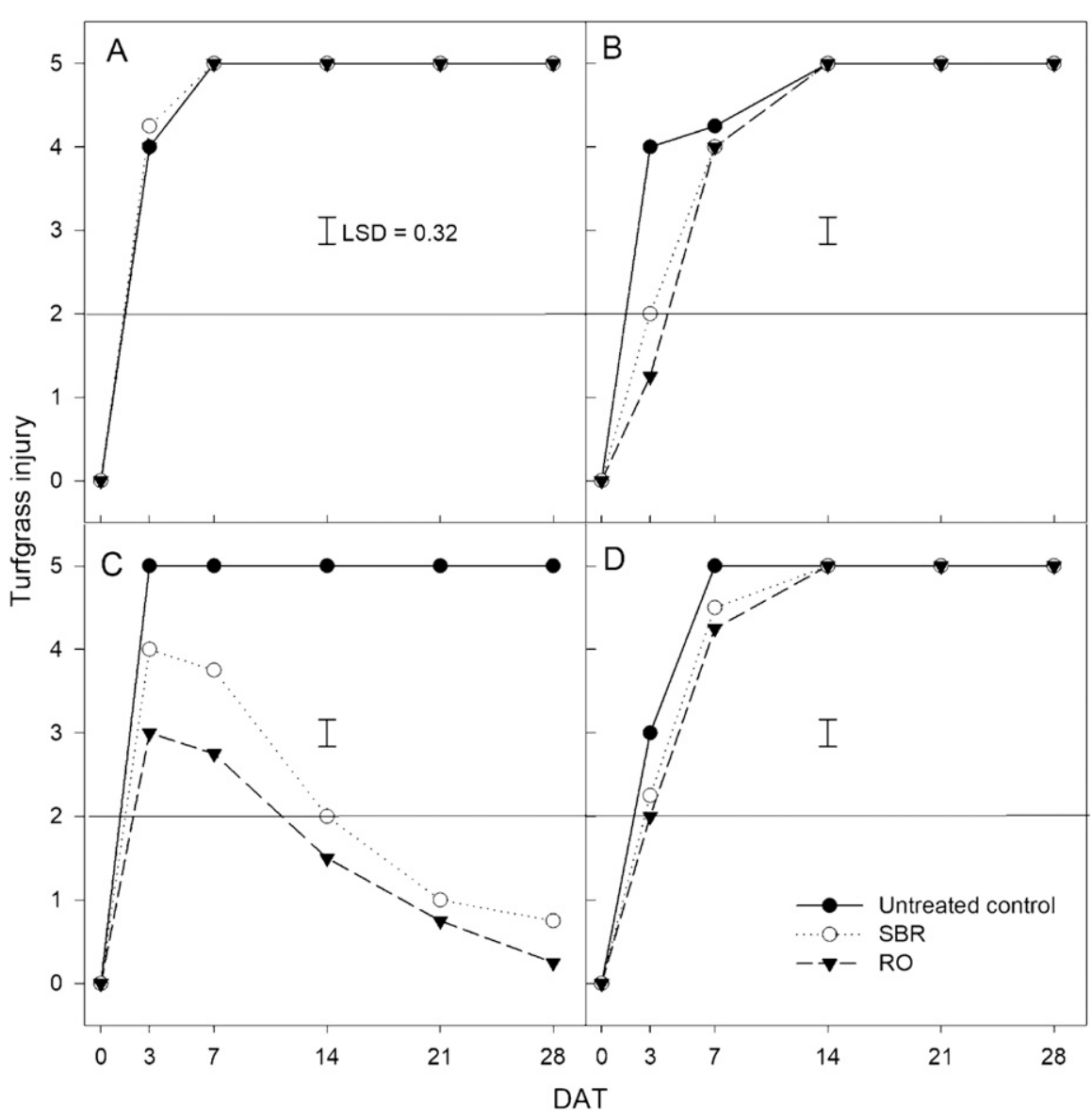

Fig. 3. Visual turfgrass injury severity ratings (0-5 scale, where 2 is minimum acceptability and 5 is brown, dead turf) of a creeping bentgrass putting green as affected by water rinse only ( $\mathrm{RO})$, detergent soap solution + brushed in + water rinse (SBR), and no remediation practice (untreated control) after simulated spill of (A) petroleum hydraulic fluid, (B) vegetable hydraulic fluid, (C) synthetic polyalkylene hydraulic fluid, and (D) synthetic diester hydraulic fluid by days after treatment (DAT) in 2012. The line at the turfgrass severity rating of 2 indicates a visual reference of minimum acceptability. The least significant difference (LSD) bar indicates the LSD value to make treatment comparisons within the evaluation date.

9.3; SAS Institute Inc., Cary, NC) using a compound symmetry covariate structure. Treatment means for significant main effects and interactions were separated using Fisher's protected least significant difference test. An alpha value of 0.05 was used to determine statistical significance.

\section{Results and discussion}

During both trial years, there was a significant three-way treatment interaction of hydraulic fluid, remediation practice, and DAT on turfgrass injury (Table 1 ), which indicates that the effect of hydraulic fluid type by remediation practice interaction varied with DAT. The treatment effect of year on the three-way treatment interaction was significant and, therefore, data from each year were analyzed separately.

Hydraulic Fluid. Regardless of year, the untreated control never displayed symptoms of turfgrass injury on any date (Fig. 1). In addition, all hydraulic fluid treatments injured turfgrass to unacceptable levels by 3 DAT and resulted in plant death by 14 DAT when no remediation practices were applied (Fig. 1). In 2011, PHF and SHFl treatments resulted in plant death by $3 \mathrm{DAT}$, whereas VHF and SHF2 did not cause plant death until 14 DAT (Fig. 1). Similarly, the following year, in 2012, the SHFl treatment resulted in plant death 3 DAT, but PHF did not kill turfgrass until 7 DAT (Fig. 1). As in 2011, VHF did not result in plant death until 14 DAT in 2012, but SHF2 caused more rapid plant death than the previous year at 7 DAT (Fig. 1).

Over both years, data indicate that turfgrass death was most rapid with SHFl hydraulic fluid whereas VHF was the slowest among evaluated hydraulic fluids if no remediation measures were taken. The other two hydraulic fluids, PHF and SHF2, varied in pace of injury during the 2 years, with plant death occurring between 7 and 14 DAT. Regardless of the pace of injury, all hydraulic fluid treatments resulted in plant death.

Remediation practice. Remediation practice effectiveness was influenced by hydraulic fluid type during both years of this trial (Table 1). The RO and SBR remediation practice treatments were effective in reducing injury in plots treated with SHF1, but not with SHF2, VHF, and PHF (Figs. 2 and 3). On turf treated with SHFl, both remediation practice treatments lowered turfgrass injury significantly compared with no remediation on all evaluation dates, and resulted in acceptable levels of turfgrass injury 14 DAT in both years (Figs. 2 and 3). The RO remediation treatment resulted in less turfgrass injury compared with the SBR treatment on two and four evaluation dates in 2011 and 2012, respectively (Figs. 2 and 3). Conversely, for the other three hydraulic fluid treatments, neither RO nor SBR remediation treatments were able to reduce injury to acceptable levels over the 28-d evaluation period (Figs. 2 and 3 ). However, in 2011, it did appear that the SBR treatment began to reduce turfgrass injury compared with no remediation at the 28 -d evaluation date for the PHF and SHF2 hydraulic treatments (Fig. 2).

All hydraulic fluids tested in this trial, regardless of chemical composition, resulted in eventual turfgrass death by 14 DAT after treatment if no remediation practices were taken immediately after application (Fig. 1). Observations of turfgrass death following spills of petroleumbased hydraulic fluids resulting from phytotoxicity agree with previous findings (Berndt, 2007; Elliott and Prevatte, 1995; Johns and Beard, 1979). As reported previously on warm-season turfgrasses (Berndt, 2007; Berndt et al., 
2017), these results demonstrated that vegetable-based hydraulic fluids caused complete turfgrass necrosis and are not considered a less phytotoxic alternative to petroleum hydraulic fluids. Without remediation practices, both synthetic hydraulic fluid treatments killed turfgrass. Other reports have noted initial turfgrass injury with synthetic hydraulic fluids on ultradwarf bermudagrass, but necrosis was not complete and slow regeneration of the turfgrass stand was observed (Berndt, 2007; Berndt et al., 2017). This discrepancy is likely related to the vigorous rhizomatous growth habit of ultradwarf bermudagrass compared with creeping bentgrass that can accelerate regeneration of healthy tissue posthydraulic fluid application (McCarty, 2005) and, possibly, to chemical composition (Berndt et al., 2018b). The RO and SBR postapplication remediation practices were not effective in lessening turfgrass injury for petroleum hydraulic fluid tested in our study despite previous work noting the effectiveness of SBR treatments (Johns and Beard, 1979; Powell, 1981). More recently, Berndt et al. (2017) reported slight decreases in injury expansion time if $\mathrm{RO}$ treatments were used after petroleum hydraulic spills, but suggested these differences might not be practical to turf managers. In addition, remediation practices were not significant in reducing injury from vegetable-based hydraulic oils in this study, as confirmed previously (Berndt et al., 2017). However, both remediation practices reduced injury in SHFl treatments significantly, but were not effective in reducing injury from SHF2. Berndt et al. (2017) also demonstrated that an RO treatment could reduce significantly turfgrass injury from SHFl. The disparity of remediation practice efficacy between the two synthetic hydraulic fluids in this study could potentially be the result of differences in chemical composition and properties (Berndt et al., 2018b), although this study did not seek to confirm this claim.

\section{Discussion}

The findings of this research indicate the severity of turfgrass injury that can occur on creeping bentgrass putting greens when hydraulic spills occur. Hydraulic fluid type did not ultimately influence turfgrass injury if no remediation practices were taken. However, remediation practices were able to minimize turfgrass injury effectively for synthetic polyalkylene glycol treatments, confirming previous reports (Berndt et al., 2017), but not synthetic diester hydraulic fluid treatments. Due to this finding, turfgrass managers might consider the synthetic polyalkylene glycol hydraulic fluid evaluated in this study as a viable alternative to conventional hydraulic fluids as long as the product meets performance expectations. Additional research is needed to confirm these results on cool-season turfgrass injury in this trial between petroleum, vegetable, and synthetic hydraulic fluids. Furthermore, testing of additional hydraulic fluid types and remediation practices on turfgrass injury in conjunction with performance characteristics to determine top-performing hydraulic fluids for the turfgrass industry would be beneficial.

\section{Literature cited}

Aislabie, J.M., M.R. Balks, J.M. Foght, and E.J. Waterhouse. 2004. Hydrocarbon spills on Antarctic soils: Effects and management. Environ. Sci. Technol. 38(5):1265-1274.

Bai, R. and D. Li. 2013. Establishment of perennial ryegrass in soil with simulated petroleum-based spills and remediation. HortTechnology 23:334-338.

Beatty, D. and M. Greaves. 2006. Polyalkylene glycol synthetic PAG oil explained. 18 Sept. 2019. <https://www. machinerylubrication.com/Read/930/ pag-synthetic-oil>.

Berndt, W.L. 2007. Effect of synthetic hydraulic fluid on warm-season turfgrass. Appl. Turfgrass Sci. 4(1), doi: 10.1094/ ATS-2007-1119-01-RS (abstr.).

Berndt, W.L. 2018. Hydrocarbon machine fluid injury on greens: What do we know? Golfdom 74(3):36-39.

Berndt, W.L., J.W. Riger, and C.W. Riger. 2017. Nonlinear regression mod- eling of hydraulic oil injury on a bermudagrass green. Intl. Turfgrass Soc. Res. J. 13(1):240-249.

Berndt, W.L., J.W. Riger, and C.W. Riger. 2018a. Kinetics of hydrocarbon induced visual green color loss on a bermudagrass green. Agron. J. 110(2):472479.

Berndt, W., J. Riger, and C. Riger. 2018b. Viscosity is linked to temporal behavior of hydrocarbon injury on a bermudagrass green. Crop Forage Turfgrass Mgt. 4(1), doi: 10.2134/cftm2018.06.0045.

Cheng, V.M., A.A. Wessol, P. Baudouin, M.T. Benkinney, and N.J. Novick. 1991. Biodegradable and nontoxic hydraulic oils. Soc. Automotive Eng. Tech. Paper Ser. no. 910964.

Elliott, M.L. and M. Prevatte. 1995. Comparison of damage to Tifgreen' bermudagrass by petroleum and vegetable oil hydraulic fluids. HortTechnology 5:5051 .

Everett, K.R. 1979. Some effects of oil on the physical and chemical characteristics of wet tundra soils. Arctic 31(3):260276.

Johns, D. and J.B. Beard. 1979. Effects and treatments of petroleum spills on bermudagrass turf. Agron. J. 71(6):945947.

McCarty, L.B. 2005. Best golf course management practices: Construction, watering, fertilizing, cultural practices, and pest management strategies to maintain golf course turf with minimal environmental impact. 3rd ed. Prentice Hall, Upper Saddle River, NJ.

Powell, A.J., Jr. 1981. Recovery of creeping bentgrass after hydraulic oil spill. Kentucky Turfgrass Res. 1981(Jan):37-46.

Sumerlin, S. 2010. How do you know if you're using the right hydraulic oil? 19 Sept. 2019. <https://www.machinerylubrication. com/Read/25967/hydraulic-oillubrication-viscosity>. 